\title{
Applicability analysis of active IR thermography and selected signal processing methods for technical conditions assessment of bridge elements
}

\author{
L. Różański* and K. Ziopaja**
}

\author{
*Poznan University of Technology, Faculty of Mechanical Engineering and Management, Piotrowo 3, 60-965 \\ Poznań, Poland, leszek.rozanski@put.poznan.pl \\ **Poznan University of Technology, Faculty of Civil and Environmental Engineering, Piotrowo 5, 60-965 \\ Poznań, Poland, krzysztof.ziopaja@put.poznan.pl
}

\begin{abstract}
Standard procedures for carrying out the inspection of the bridge, or the assessment of its technical condition and suitability for use, rely on visual assessment made by the inspector and are in a certain part subjective. The aim of the article is to analyze the applicability of IR as a tool to support the inspections of the structure and equipment elements of bridges. We are looking for the relationship between temperature distribution on an element surface (registered by an infrared camera) and hidden defects, which may be associated with e.g. corrosion, fatigue, stress concentration in steel structures or moisture, discontinuity or delaminations in concrete structures. Due to low sensitivity of the temperature field on small disturbances generated by subsurface damage, the improvement of the efficiency of the method is sought in additional mathematical processing of the signal, for example using discrete or continues twodimensional wavelet transformation.
\end{abstract}

\section{Introduction}

Due to the advantages of the application of NDT methods, namely their non-invasiveness, non-contact and global character (versatility), among others, not to mention their applicability (use) in new fields of applications, they are constantly being developed. This rule also applies to active infrared thermography. Active (dynamic) IR thermography is commonly used to detect material defects (inclusion), internal voids, delaminations or differences in the surface properties (e.g., caused by moisture). The report [9] presented a performance evaluation and rating of commercially available 12 remote sensing technologies for infrastructure condition assessment, specifically bridges. One of the first applications to analyze surface moisture of a small stone arched bridge was presented in [2]. Improvements in parameters of modern measuring infrared equipment (resolution and sensitivity) can improve the technical condition assessment of selected bridge elements. An investigation procedure to study masonry arch bridges, including two in-situ NDT methods and numerical analysis, is presented in [1]. Advanced experiments in detection of through-deck type fatigue cracks in a steel deck, using lock-in thermography, under point load and traveling wheel load is shown in [4]. The use, comparison and combination of two NDT methods (impact-echo and IRT) to detection of simulated delaminations and cracking defects in full-scale reinforced concrete bridge deck model are described in [5]. This article is a continuation of the research [8] and aims to examine the possibilities and limitations in detecting defects in bridges using IR thermography and several signal processing techniques. In the work [10] the efficiency of damage detection was studied basing on three classes of temperature fields: obtained from numerically simulated experiments using FEM, from similar experiments but with the addition of white noise and from real experiments. The paper [7] demonstrates how the wavelet analysis can be used as an alternative tool to fast Fourier transform in case of lock-in and pulse phase thermography in detection of defects.

\section{Infrared thermography as NDT method}

Infrared active thermography is a measuring technique requiring an external excitation source of energy to induce a temperature difference between defective and non-defective areas in the specimen under examination. Different methods of optical stimulation such as pulsed thermography (PT), pulsed-phase thermography (PPT) or lock-in thermography (LT) to test the feature of the different kinds of material can be used for construction and maintenance of bridges (steel, reinforced concrete, various kinds of paint etc.). In civil engineering, in addition to active thermography, for damage detection to thermal insulation and tightness roof insulation of buildings, is also successfully passive thermography applied. Thermograph type FLIR T620 (FPA detector 320x240; thermal resolution NETD - 0.05K; spatial resolution $0.68 \mathrm{mrad}$ ) for acquisition of thermal imaging was used to carry out the measurements.

\section{Damage detection - real bridge}

In the evaluation of the technical conditions of engineering structures, the key role is played by the inspection carried out by the experienced specialist or the group of specialists. On-site verification (the inspection of the structure) performed from the level of the road (from the top) as well as on the level of the bottom girders gives a wide range of 
crucial qualitative information about the bridge condition. Depending on the kind of the inspection, the direct access to the structure elements should be possible from the distance of $\min .1 .0 \mathrm{~m}$. On the basis of on-site inspections which are expanded to include possible field trials (for instance $\mathrm{pH}$ records of concrete, chloride contents in it, hammer tapping, geodesic measurements), some conclusions which assign to particular elements specific technical condition feature are specified. This process is formalized in order to simplify and shorten the inspection and because of the abovementioned reasons it might not be objective. However, it must be emphasized that the purpose of the inspections (the detection of possible damages which may influence the safety of the structure and its users) is accomplished.

We will try to answer the question if infrared passive thermography can extend and complement the detection and identification of damages of bridge elements on the example of a road viaduct. The research works were conducted from the ground level under the extreme viaduct span where the vertical clearance was not so high. The distance from the IR camera and the viaduct was about $1,0 \div 2.5 \mathrm{~m}$.

Analysed structure is located in Poznań in Nowe Miasto District. The viaduct is situated along Kurlandzka Street over the dual Bolesław Krzywousty road and over two smaller access roads. The average daily traffic rate over and below the viaduct is very high. The structure was built in the second half of the 70 s of the previous century.
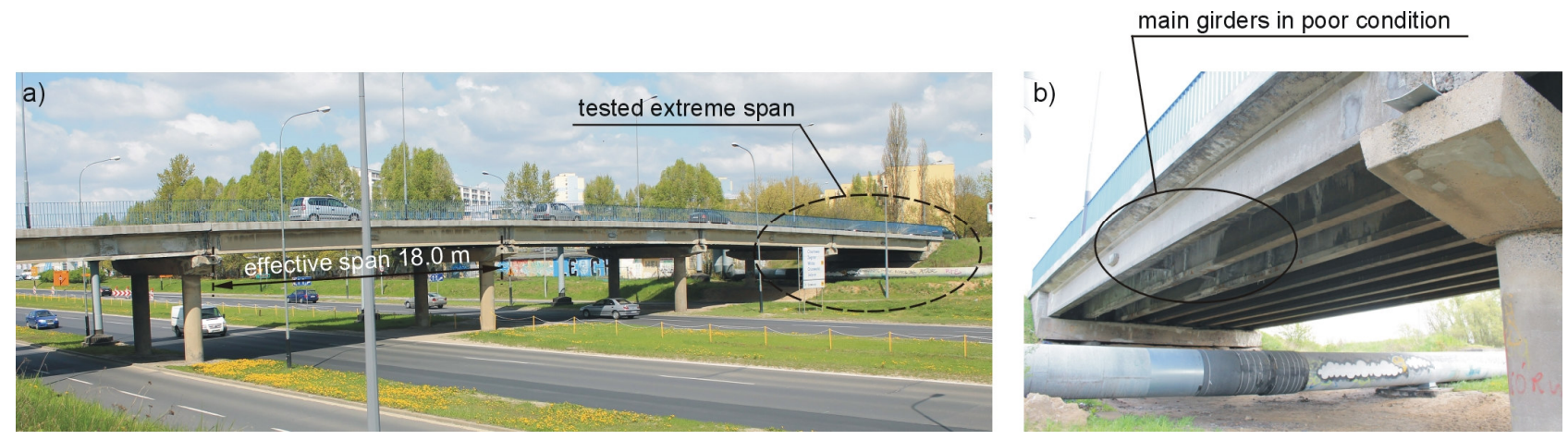

Fig. 1. Partial view of the viaduct: a) marked span, which has been tested with the use of an infrared camera, b) tested span from the bottom of

The analysed viaduct is multi-spans system in the statical scheme of simply supported beams. The structure in the cross section consists of 8 prefabricated post-tensioned concrete beams of the WBS system which are $1.0 \mathrm{~m}$ high and set with spacing of $1.42 \mathrm{~m}$. Theoretical spans length are $6 \times 18.0 \mathrm{~m}$. The length of the whole structure is about 112.3 $\mathrm{m}$. It must be emphasized that no drainage system was built except to add some inclinations of surfaces of road pavements and longitudinal inclinations of the structure itself. Figure 1 presents photos of the part of viaduct and the area of inspection was marked with the use of an infrared camera. Figure 2 presents the drawing of the cross-section with description of viaduct layers over the roadway.

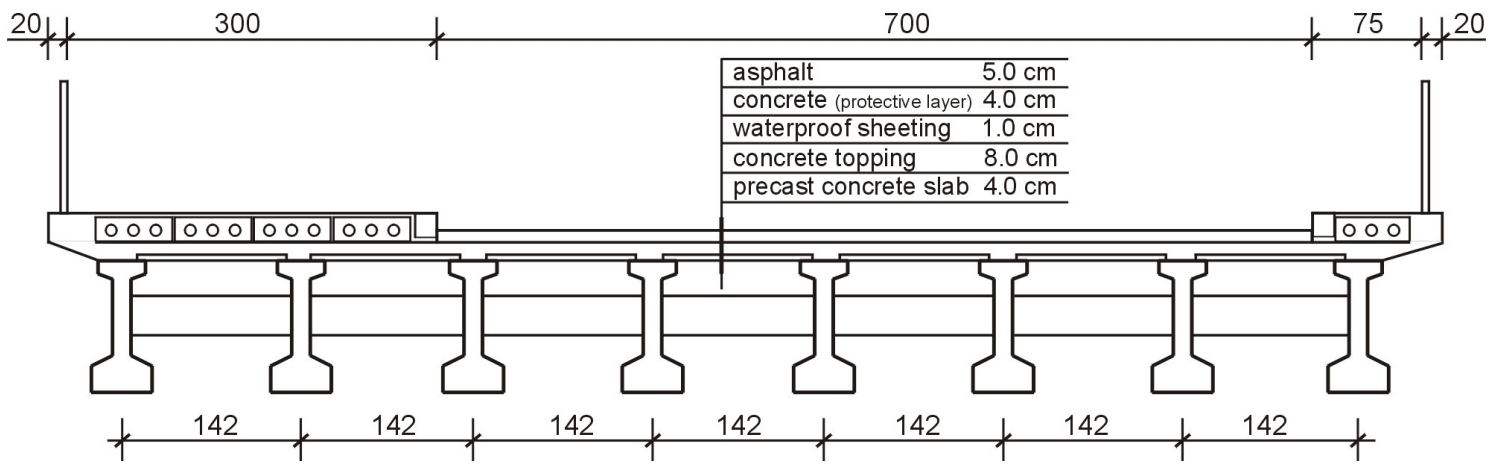

Fig. 2. Schematic cross-section of the viaduct

The abutment (shown in Fig.1) is built of two reinforced concrete columns of diameter of $90 \mathrm{~cm}$ which are combined with a massive cap, two wing walls and a back wall. The cap is partly covered by the ground of embankment. The WBS beams have been rested on the cap using tangential steel bearings. There are no expansion joints between concrete span and the back wall of abutment. The typical shape of the longitudinal inclination of the pavement on the structure caused that the substantial amount of rainfall flows in the direction of the analysed abutment. Together with the damaged waterproofing layer this inclination has a very negative influence on the technical condition of the edge pier as well as on some parts of span.

On the large vertical surfaces of the abutment cap some protective layer of concrete fell off. On other areas there are shortages of adhesion of this layer. There is also a lot of visible flaking of concrete. It was probably caused by 


\subsection{1/qirt.2016.157}

corrosion of reinforcement, small thickness of the cover layer $(1.5 \mathrm{~cm}$ for stirrups and $2.5 \mathrm{~cm}$ for main bars), carbonation and chemical corrosion of concrete. In the neighbourhood of longitudinal bars of the cap (both top and bottom) there are longitudinal cracks of different length. The causes must be similar to the abovementioned ones.

a)

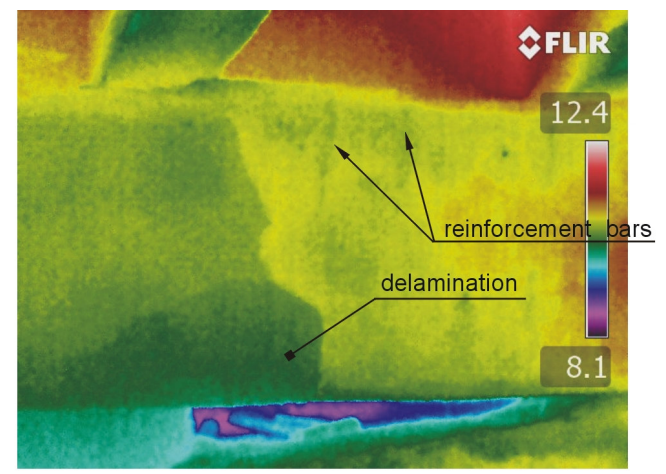

b)

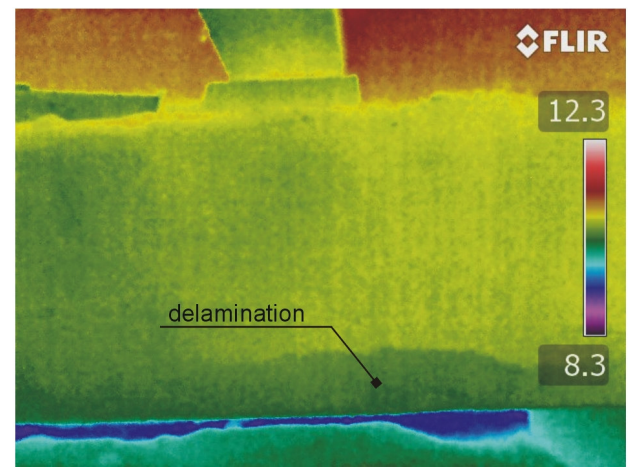

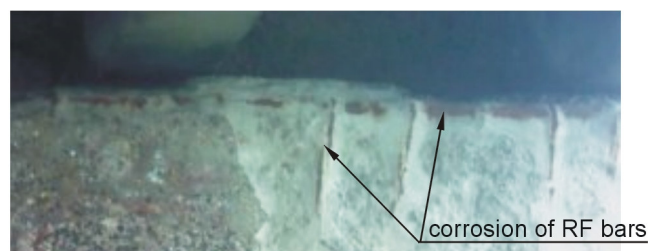

lack of concrete cover
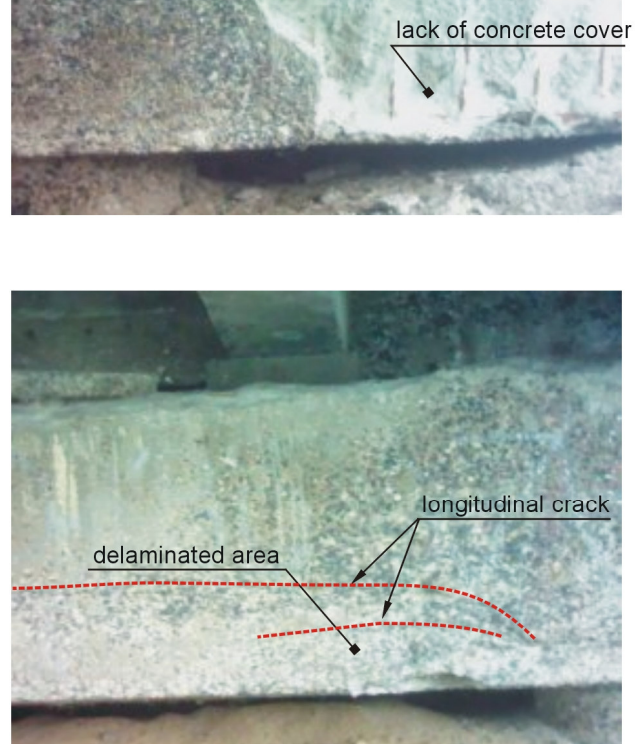

Fig. 3. Passive IR-thermography test results of RC abutment cap:

a) infrared image and photo of the extreme section

b) infrared image and photo of the intermediate section

The intermediate pier is in far better technical condition than the abutment. There are less cracks and they do not seem to be so intense. Only in the section near the expansion gap between two adjacent spans some intensely wet and degraded areas of concrete have been noticed. Due to lack of integrity and leakage of the surface, water flows on the edges of girders and reaches the end of the capping beam. Such long-term state leads to chemical corrosion of concrete and the occurrence of corrosion in reinforcement, leaching corrosion of concrete, which can weaken seriously the endangered sections of the support. It is noted that many places of delaminations of the concrete cover, intensive spalling and large losses or cracking of concrete have recently been provisionally repaired.
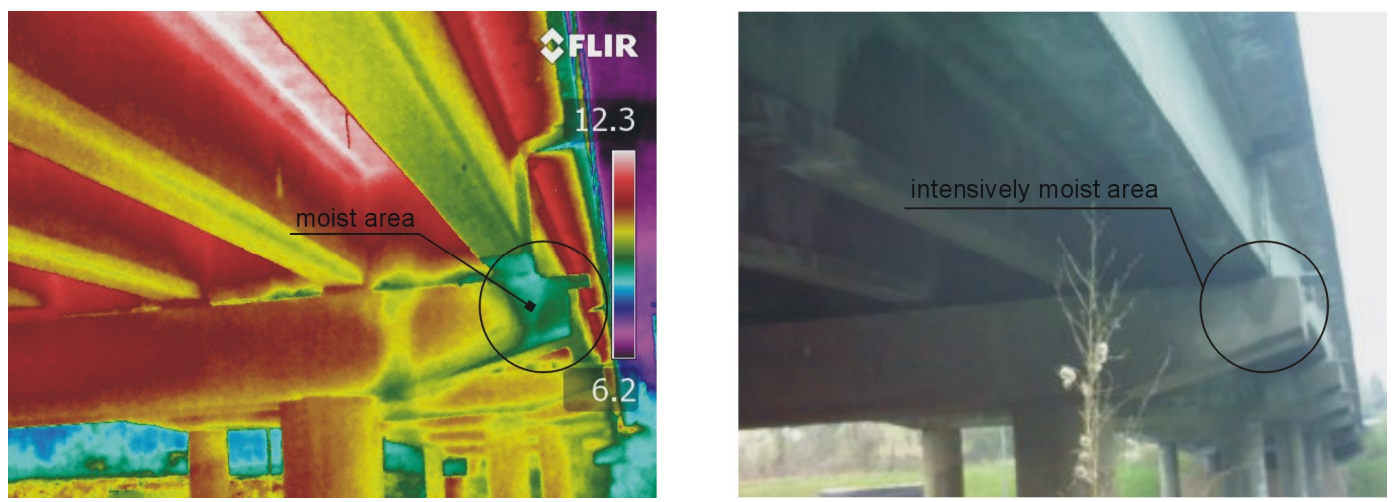

Fig. 4. Passive IR-thermography test result of intermediate $R C$ pier cap: infrared image and photo

Currently the bridge has a new road surface of asphalt concrete and the bituminous surface on both pavements. Nevertheless, these repairs have not improved the actual technical condition of the bridge girders and deck owing to the fact that no repairs or exchange of hydroinsulation have been carried out, not to mention the lack of expansion joints. 


\subsection{1/qirt.2016.157}

The observation of bottom of the plate with the use of an infrared camera in the dry areas has shown temperature uniformity without any disruptions. However, in many areas where the insulation of the plate is in a critical state, some wet places, runs and efflorescence along the cracks in precast concrete slabs extending toward the main girders are visible. The penetration of water seems to be so intense and long-term that some stalactites have been formed. It proves the intensity of leaching and chemical concrete corrosion. Numerous rusty streaks inform about strong corrosion of reinforcement of precast concrete slabs (nevertheless, there are no cracks or delaminations in the covering layer of concrete). The examples of the abovementioned damages are shown in Fig. 5b.

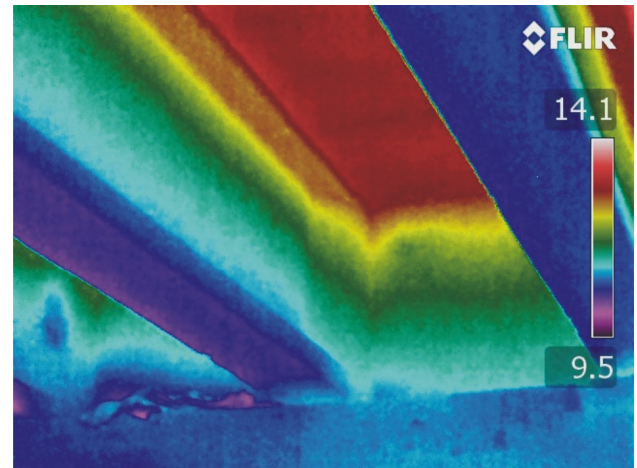

b)

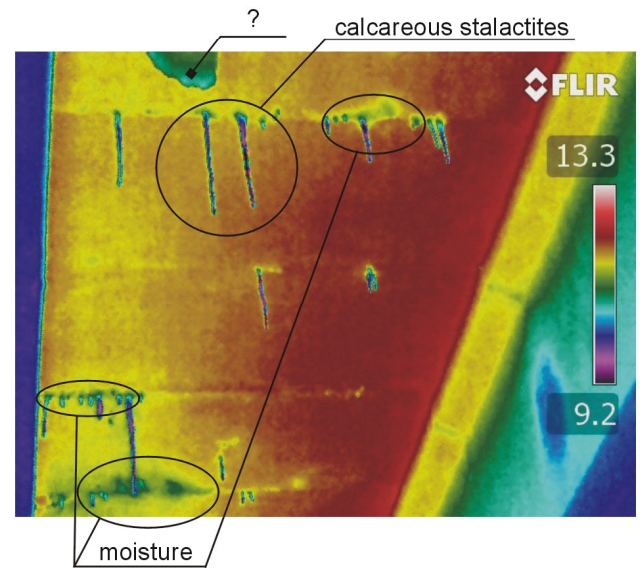

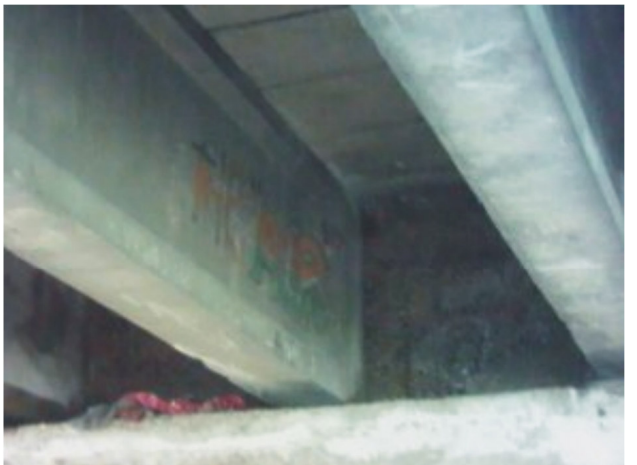

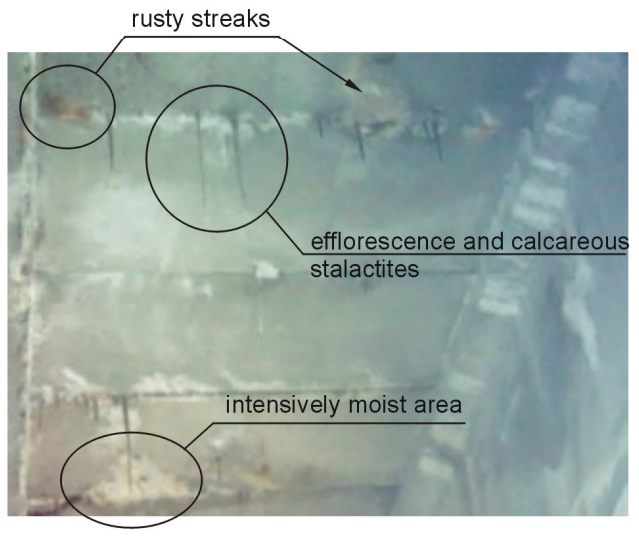

Fig. 5. Passive IR-thermography test results of the underside of deck slab: a) infrared image and photo of the section in satisfactory condition b) infrared image and photo of the section in serious condition

Damages of the girders may be divided into two groups. The first group of damage threatens the safety of the structure and the second group decreases durability and worsens aesthetic. The first group includes corrosion of prestressing strands, corrosion of the anchor blocks and degradation of concrete in the immediate area of the anchor blocks. Observed on the underside of girders rust-colored streaks and losses of concrete cover (Fig. 6a, b) are the best evidences of advanced corrosion. Unfortunately, passive IR thermography can not give any answers about the condition (state) of prestressing steel bars. Poor condition of the concrete anchorage zone tendons (Fig. 6c) also can not be verified by means of passive thermography. Passive thermography can help only in assessment of the moisture degree and area of tested concrete surface.

Temperature differences, that are shown on the thermograms (Fig. 3,4,5 and 6), are associated with different values of coefficients of emissivity degraded areas related to chemical corrosion and electrochemical corrosion of concrete reinforcing bars. The value of the observed temperature difference shown by the IR camera depends mainly on the temperature difference of the bridge and radiation temperature reflected from the surface of the bridge in the direction of the camera. In the case of delamination the situation is different. We are dealing here with the occurrence of natural IR active thermography which is associated with the appearance of daily cyclical temperature changes (sunshine, rain, wind, amount of traffic etc.) and the formation of different temperature gradients between areas that have not been and have been delaminated. Therefore, on thermograms it is possible to observe potentially delaminated areas. 


\subsection{1/qirt.2016.157}

a)
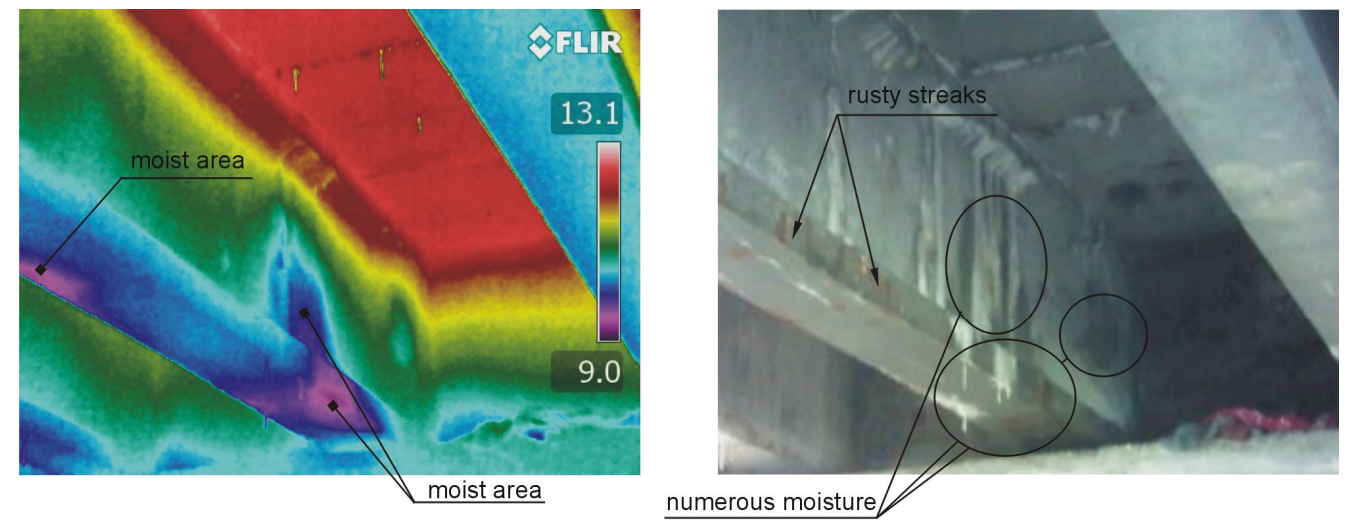

b)
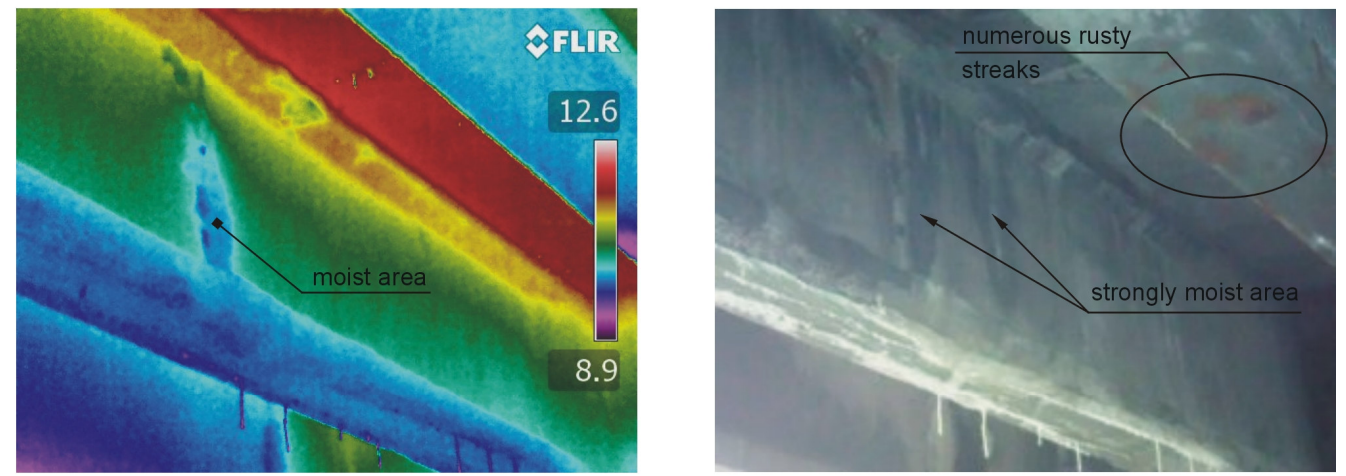

c)
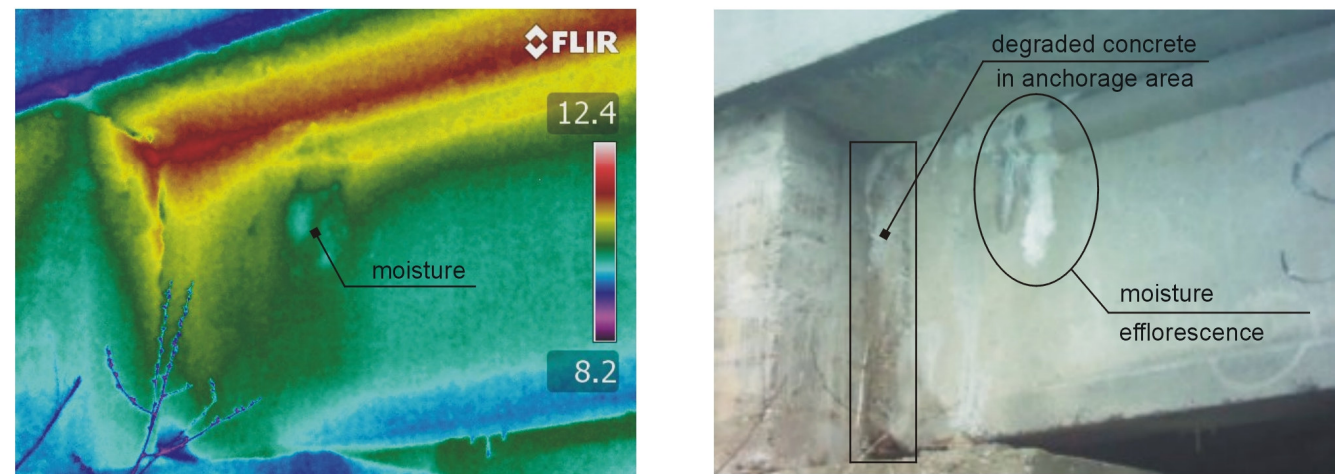

Fig. 6. Passive IR-thermography test results of the prestressed I girders:

$a, b)$ infrared image and photo of two different WBS type beams

b) infrared image and photo of external I girder at the abutment

\section{Damage detection - numerical analysis}

\subsection{Problem formulation}

The aim of the study is firstly, detect internal damage zones in the structure providing that such zones exist; secondly, it is an introduction to laboratory tests and examination of real bridge structure. Homogenous (steel) and nonhomogenous (reinforced concrete) 3D structures are subjected to arbitrary thermal excitation. Typical non-stationary heat flux problems are considered. Experiments are numerically simulated in Abaqus/Standard software. On the boundary portion $\Gamma_{\mathrm{T}}, \Gamma_{\mathrm{q}}, \Gamma_{\mathrm{h}}$ of the structure $\Omega$ the Dirichlet, Neumann and Henkel boundary conditions are specified, respectively:

$$
\begin{cases}T(x, t)=T^{0}(x, t) & \text { on } \Gamma_{T} \\ q_{n}(x, t)=q_{n}^{0}(x, t) & \text { on } \Gamma_{q} \\ q_{n}(x, t)=h\left[T(x, t)-T_{\infty}(x, t)\right. & \text { on } \Gamma_{h} \\ T(x, t=0)=T_{0} & \text { in } \Omega \cup \Gamma\end{cases}
$$


, where $T^{0}(\mathrm{x}, t)$ is the excitation temperature, $q_{n}{ }^{0}(\mathrm{x}, t)$ is the heat flux density, $h$ is a convection (film) coefficient and $T_{0}$ is the initial condition. Symbol $T_{\alpha}(x, t)$ means the environmental temperature. The model of a system with damage identification procedure is shown in Fig. 7. The structural response (temperature field) is measured in two ways. Once, this is done on one side of the plate, while the thermal excitation is performed on opposite side of the plate. The second way is that the temperature measurement is carried out during cooling process on the surface, which was previously heated. Subsequently the measured response signal is analyzed using 2-D discrete wavelet transform. Local disturbances of transformed signal indicate the possibilities of damage zones.

\subsection{Discrete Wavelet transform}

Wavelet Transform (WT) is a mathematical tool, which have been successfully used in active IR thermography $[3,6]$ to the analysis of thermographic data. The main advantage of WT is its usefulness in damage identification problem solving. Because it facilitates the extraction of the signal information on local disturbances and discontinuities that may be caused by hidden defects. Theoretical background and practical applications of the WT was published in the early 1990s by Ingrid Daubechies, C.K. Chui, Y. Mayer and D.E. Newland. In 1989 Stephane Mallat presented the algorithm of multiresolution decomposition of two-dimensional signal $F(x, y) \in L^{2}$ in the wavelet representation:

$$
F(x, y)=S_{J}(x, y)+\sum_{j=1}^{J} D_{j}^{V}(x, y)+\sum_{j=1}^{J} D_{j}^{H}(x, y)+\sum_{j=1}^{J} D_{j}^{D}(x, y)
$$

, where the symbol $s_{j}, D_{j}^{V}, D_{j}^{H}$ and $D_{j}^{D}$ correspond with the smoothened part of the image, and with vertical, horizontal and diagonal detail of the image, respectively. Maximal level of DWT $J$ depends on the number of points $N$ used for approximation of the function $F(x, y)$ and is equal $N=2^{J}$. Representation of the signal on the level $j$ is the sum of vertical, horizontal and diagonal components:

$$
D_{j}(x, y)=D_{j}^{V}(x, y)+D_{j}^{H}(x, y)+D_{j}^{D}(x, y) .
$$

Detail $D_{j=1}(x, y)$ is corresponding to the most local representation of the function $F(x, y)$.

\subsection{D homogenous structure}

The model of the first example is presented in Fig. 7. Let us consider a steel plate (Fig. 7c) with dimensions $100.8 \times 49.6 \times 8 \mathrm{~mm}$ and the following material parameters: density $\rho=7850 \mathrm{~kg} / \mathrm{m}^{3}$, thermal conductivity $\lambda=50 \mathrm{~W} /(\mathrm{m} \cdot \mathrm{K})$ and specific heat capacity $\mathrm{c}=450 \mathrm{~J} /(\mathrm{kg} \cdot \mathrm{K})$. Temperature field is measured on one side of a structure, while the thermal excitation is on the opposite side of the plate. Convection coefficient for all surfaces except the back one is $h=8.0$ $\mathrm{W} /\left(\mathrm{m}^{2} \cdot \mathrm{K}\right)$. The initial temperature is $20^{\circ} \mathrm{C}$. Temperature field is measured on one side of a structure, while the thermal excitation (Dirichlet boundary condition) is uniformly distributed on the opposite side and is variable in time as shown in Fig. $7 \mathrm{~b}$. Hence, the transverse transient heat transfer problem will be analyzed. Assume that defect has the form of an inclusion of a material with reduced thermal conductivity $\left(\lambda_{d}=40 \mathrm{~W} /(\mathrm{m} \cdot \mathrm{K})\right)$. Let it have the dimensions of $5 \mathrm{FEM}$ elements and be hidden inside the plate (the second layer from measuring surface). Numerical model of the plate consists of 5 layers, each $1.6 \mathrm{~mm}$ thick. Diffusive heat transfer 8-node linear brick finite element DC3D8 1.6x1.6x1.6 mm is used in the analysis.

a)

sorroundings $(T, \mathrm{~h})$

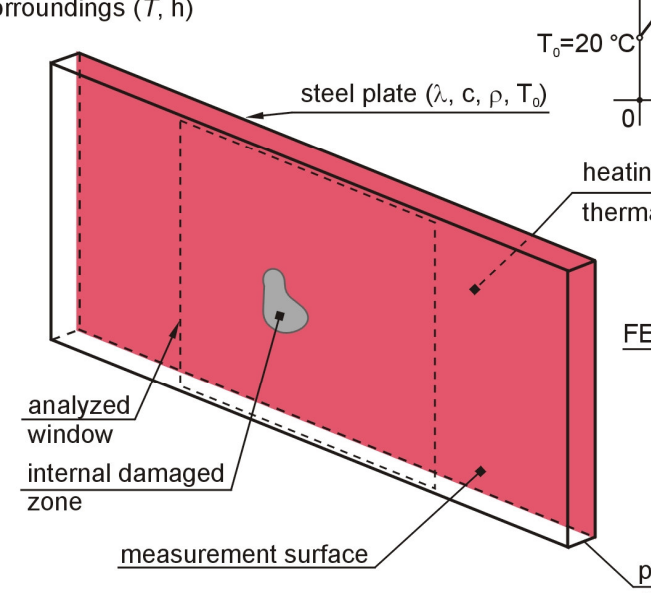

b) $i^{\mathrm{T}\left[{ }^{\circ} \mathrm{C}\right]}$

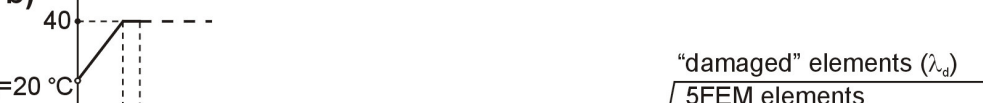

$\begin{array}{rll}{[s]} & c)\end{array}$ c) $(0.256 \%$ of whole surface $)$

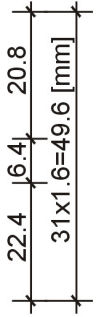




\subsection{1/qirt.2016.157}

Fig. 7. Damage identification procedure in homogenous 3D structure (Example 1):

a) model of system

b) thermal excitation model (Dirichlet boundary condition)

c) FEM 3D model with damage zone

Conducted analyses of numerical heat transfer and wavelet analysis of the temperature measured on the surface of the sample, lead to the following conclusions. Due to the advantageous properties of the wavelet analysis detection of area with different thermal conductivity inside the sample is possible. The effectiveness of damage detecting depends on its size relative to the depth of the surface, on which the temperature measurement is carried out, on environmental conditions and on the parameters of the heat pulse. The measurement time does not play an important role. The simple Haar wavelet and some of the Daubechies wavelet family proved to be the best for visualization of the defect (Fig. 8).
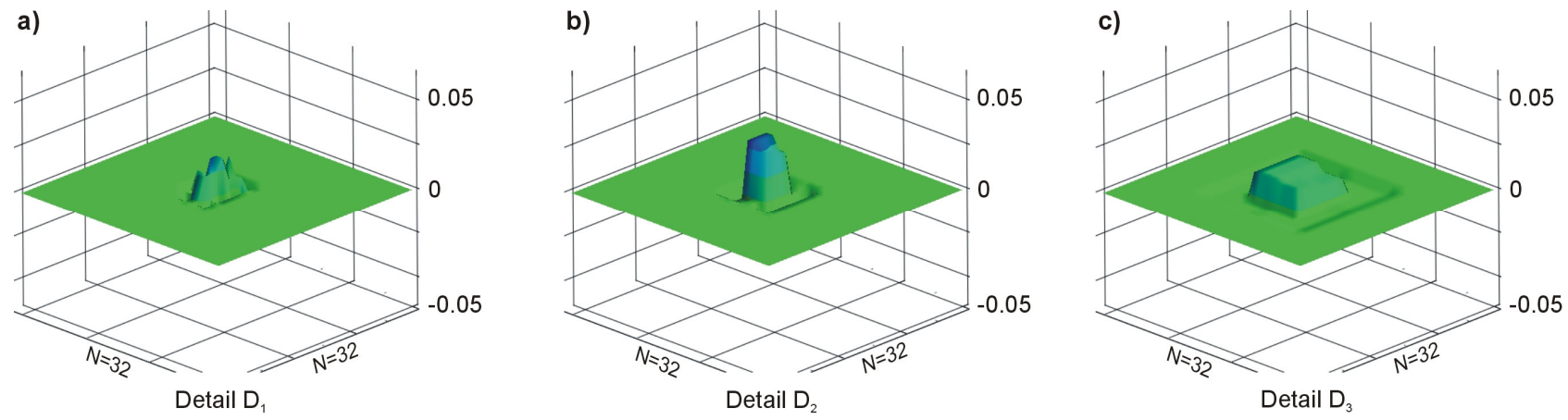

Fig. 8. Graphs of the 2-D DWT of temperature field using Haar function, time=2.14 s:

a) detail $D_{1}$, b) detail $\left.D_{2}, c\right)$ detail $D_{3}$

The second example differs from the previous one the parameters of heat excitation (the other surface is heated and thermal input is different in nature - Fig. 9b). Additionally, a different value of thermal conductivity reduction in the area of the defect $\left(50 \%-\lambda_{d}=25 \mathrm{~W} /(\mathrm{m} \cdot \mathrm{K})\right)$ was assumed. The temperature recording time plays an important role. Cooling of previously heated surface of plate due to natural convection (Henkel boundary condition; Eq. 1), results in rapid disappearance of local temperature changes generated by the defect. With time the chance to locate damage decreases (Fig. 10). Damage detection by analyzing the temperature distribution of the element surface requires precise and appropriately strong heat source and a camera with possibly high recording frequency of complete thermal images. Numerical analyzes also show the sensitivity of damage detection when noise is added to the recorded temperature signal.

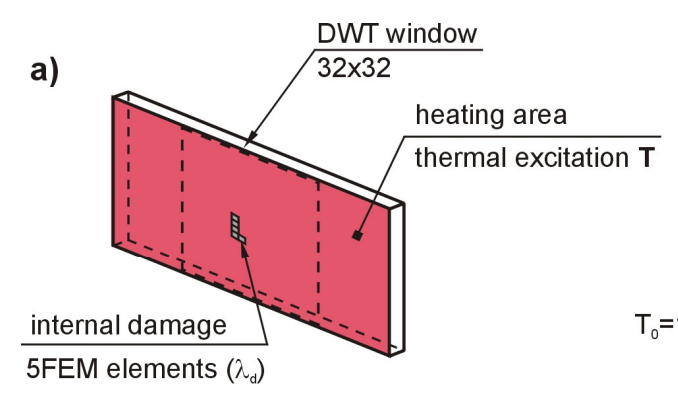

b)

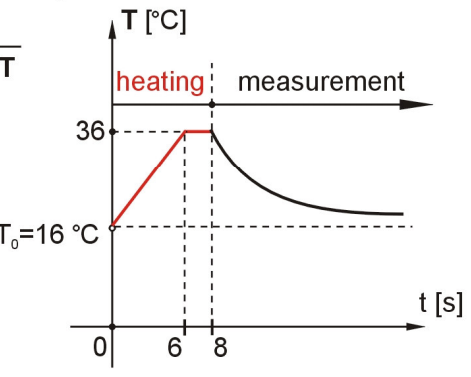

c)

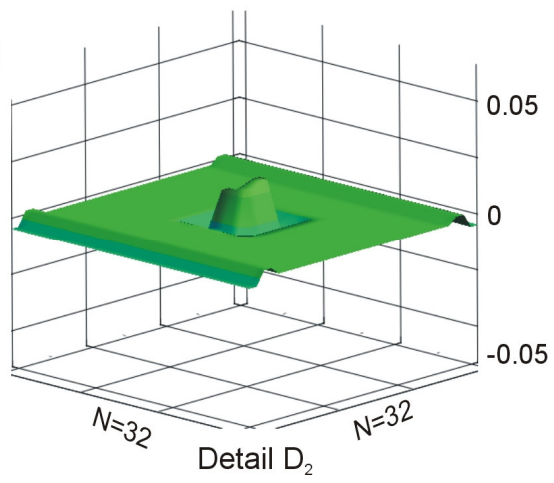

Fig. 9. Damage identification procedure in homogenous 3D structure (Example 2):

a) model of system

b) thermal excitation model (Dirichlet boundary condition)

c) graph of the 2-D DWT of temperature field using Haar function, time $=0.2 \mathrm{~s}$, detail $D_{2}$ 

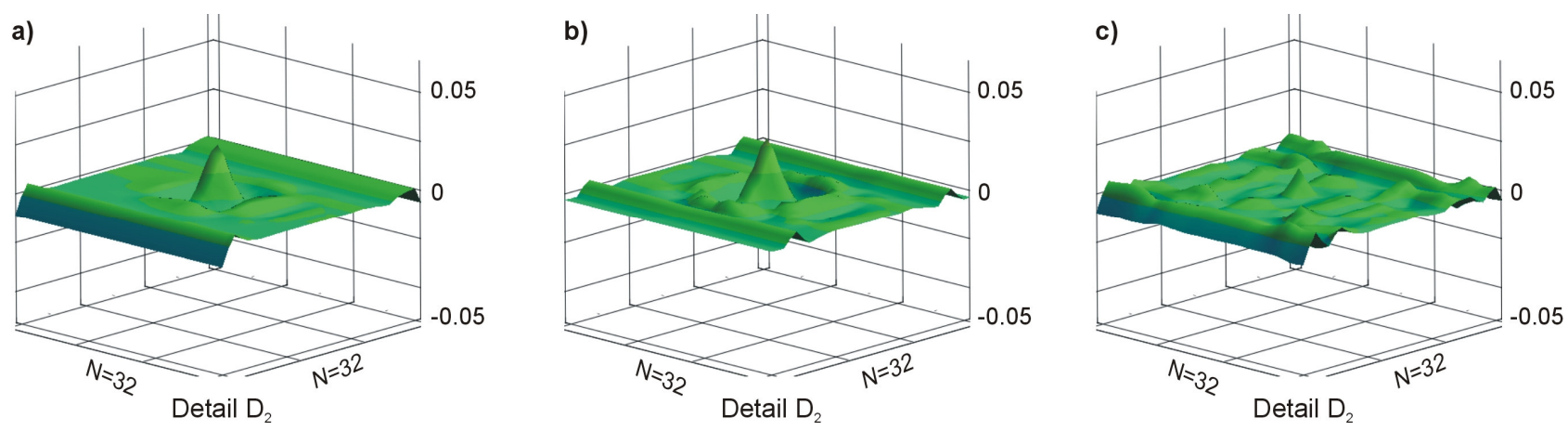

Fig. 10. Graphs of the 2-D DWT of temperature field using Daubechies 6 wavelet, detail $D_{2}$ :

a) time $=0.2 \mathrm{~s}, \mathrm{~b})$ time $=0.5 \mathrm{~s}, \mathrm{c}$ ) time $=1.3 \mathrm{~s}$

\subsection{D non-homogenous structure}

A new class of problems is faced when the structure is non-homogeneous, since the disturbances of the signal can be generated both, by jumps of material parameters and by defects. We will study this issue by the way of an example of a reinforced concrete $(\mathrm{RC})$ plate $63 \times 63 \times 8 \mathrm{~cm}$, shown in Fig. 11. The FEM mesh was generated introducing eight layers: $8 \times 1.0 \mathrm{~cm}$. The parameters of concrete are: density $\rho=2400 \mathrm{~kg} / \mathrm{m} 3$, thermal conductivity $\lambda=4.0 \mathrm{~W} /(\mathrm{m} \cdot \mathrm{K})$, specific heat $\mathrm{c}=1050 \mathrm{~J} /(\mathrm{kg} \cdot \mathrm{K})$, and for steel: $\rho=7850 \mathrm{~kg} / \mathrm{m}^{3}, \lambda=50 \mathrm{~W} /(\mathrm{m} \cdot \mathrm{K}), \mathrm{c}=450 \mathrm{~J} /(\mathrm{kg} \cdot \mathrm{K})$. In numerical model we neglect thermo-mechanical coupling and local effects in the interface between steel and concrete. The defects are modeled in the form of voids in concrete and corrosion of reinforcement. The location of defects is illustrated in Fig. 11b. Defect 1 is an air void in concrete in second layer and has the dimensions $2.0 \times 3.0 \times 1.0 \mathrm{~cm}$ (6FEM DC3D8 elements). Defect 2 takes the form of 5FEM elements in main bar (3-rd layer) with reduced thermal conductivity $\left(\lambda_{d}=5.0 \mathrm{~W} /(\mathrm{m} \cdot \mathrm{K})\right)$.

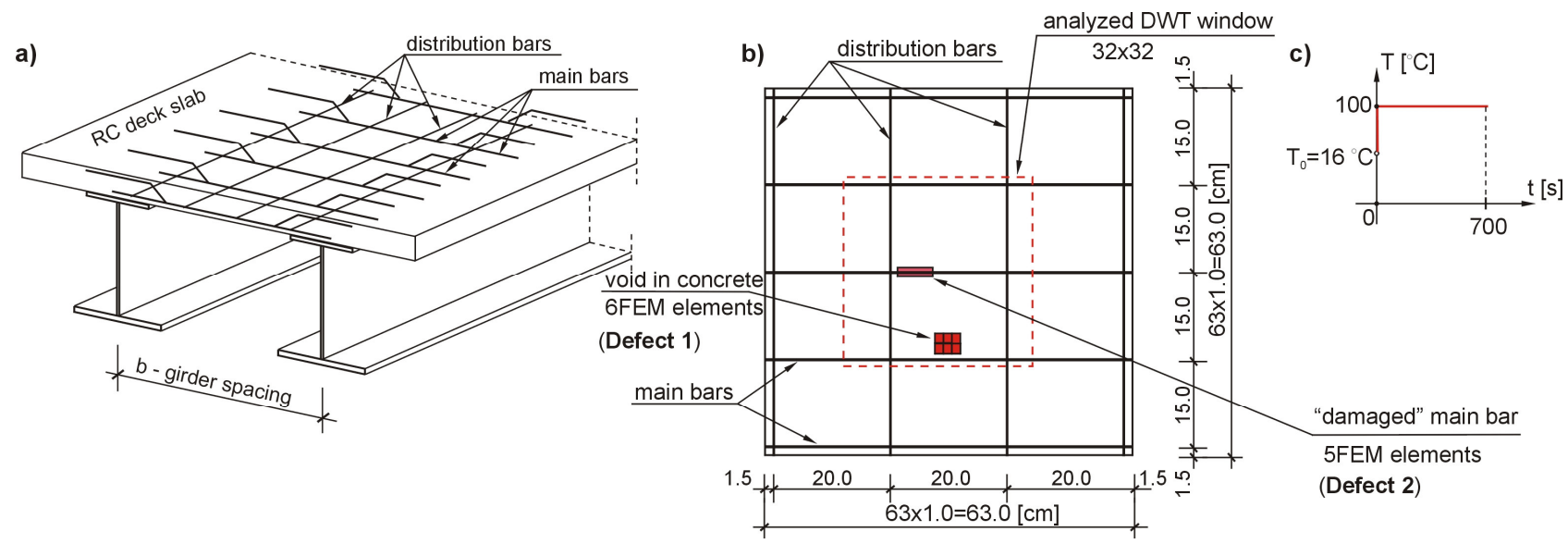

Fig. 11. Damage identification procedure in non-homogenous 3D structure (Example 3): a) model of bridge

b) model of reinforced concrete (RC) plate with defects localization c) thermal excitation model (Dirichlet boundary condition)

At this stage study, numerical analyses have been limited to induce heat flow across the plate. It is obvious that for practical and physical reasons heating plate from the top is difficult or impossible to perform. The simplification allowed to focus on evaluation of effects of the wavelet transform decomposition of temperature distribution. The influence of time of measurement is ignored, because detection of the defect is possible just since the heat wave front reaches the opposite plate surface. Due to the thermal conductivity of concrete the heat transfer is slow and takes seven hundred sec in this measurement, so defect detection is not possible before the end of 500 seconds. This is interesting that at first glance we do not see any difference in surface temperature the thermogram (Fig. 12b). This is probably caused by the limitations of image resolution. Only at high magnification of area over the defect, small differences in the temperature distribution are visible (Fig. 12c). Interesting thing is not to detect the localization of fault (the peak in Fig. 12a), but to get a structured disorders transform system, which is closely connected with the system of reinforcement (e.g. Fig. 14b). 
a)

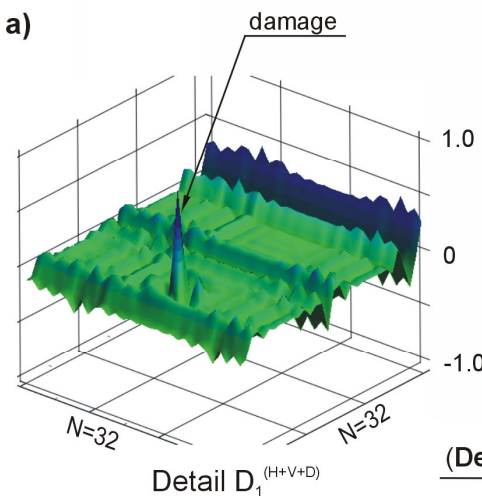

b)

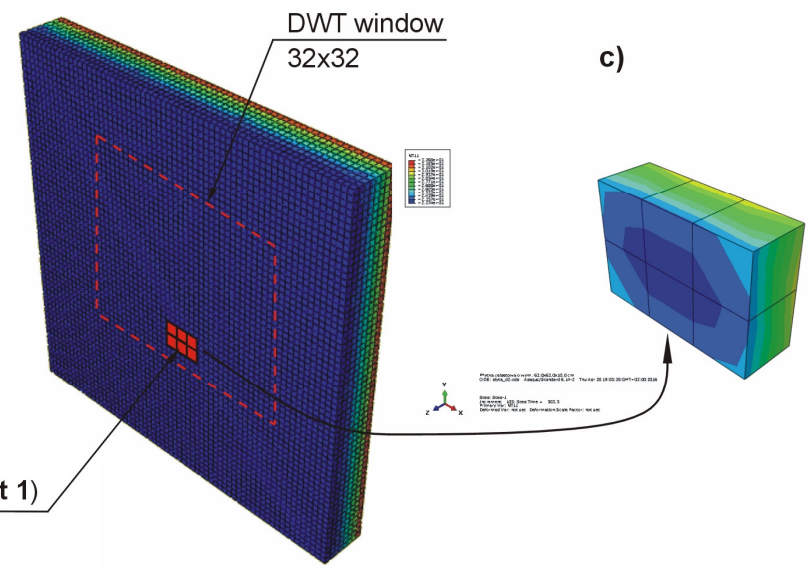

Fig. 12. Results of wavelet and numerical analysis (Example 3, defect 1):

a) graph of the 2-D DWT of temperature field using Daubechies 4 wavelet, time $=504.0 \mathrm{~s}$, detail $D_{1}$

b) FEM model of RC plate with temperature distribution

c) enlarged area over the place of defect 1

It is much more difficult to detect reinforcement discontinuities due to e.g. corrosion. The simple assumption was adopted that the conductivity of the bar on a small section $(5 \mathrm{FEM}-5.0 \mathrm{~cm})$ is strongly reduced $\left(\lambda_{d}=5.0 \mathrm{~W} /(\mathrm{m} \cdot \mathrm{K})\right)$. In order to facilitate interpretation of the 2-D DWT graphs the results of analyzes with defect were compared with these without it. It has led to some interesting conclusions. We found that in order to improve detection and localization of defect it is preferable to analyze the individual components of the detail decomposition (Eq. 2) than their sum. A similar conclusion has already been given in [10].
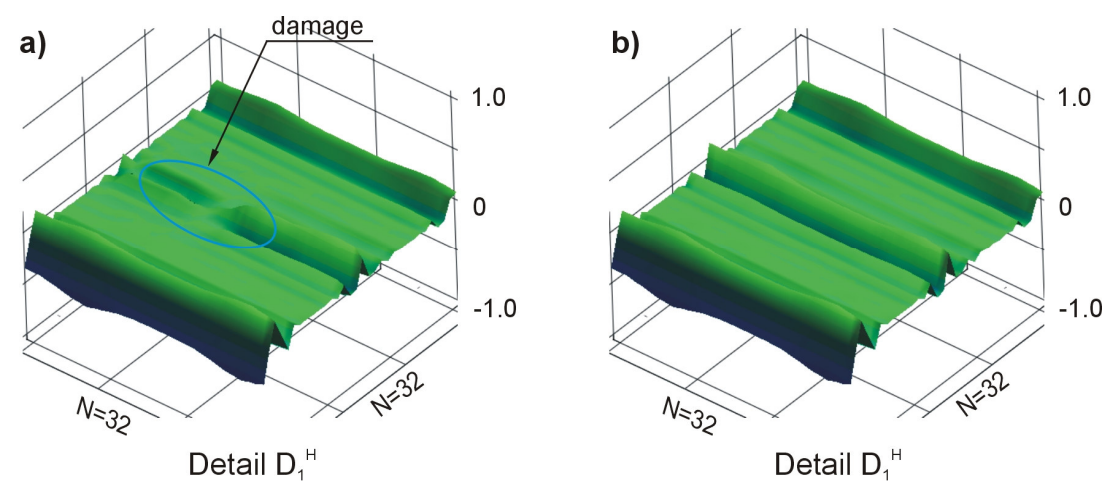

Fig. 13. Graphs of the 2-D DWT of temperature field using Daubechies 4 wavelet, time=504.0 s, (Example 3, defect 2):

a) graph of detail $D_{1}{ }^{H}$ with defect 2

b) graph of detail $D_{1}^{H}$ without defect 2

The temperature distribution in the discrete wavelet analysis is understood as a matrix of dimension $J \times J$. Wavelet which analyzes that signal moves independently along the following rows, along each column and diagonal. Thus the disturbances of DWT (Fig. 13a) at the location of the defect 2, was formed because the defect was oriented transversely to the direction of wavelet movement. In this case, the detail $D_{1}$ has only a horizontal component $D_{1}{ }^{H}$. Other components of detail $D_{1}$ do not contain any important information about the defect. When we consider all components of the transform signal, it is very difficult to set the location of damage (Fig. 14a). 

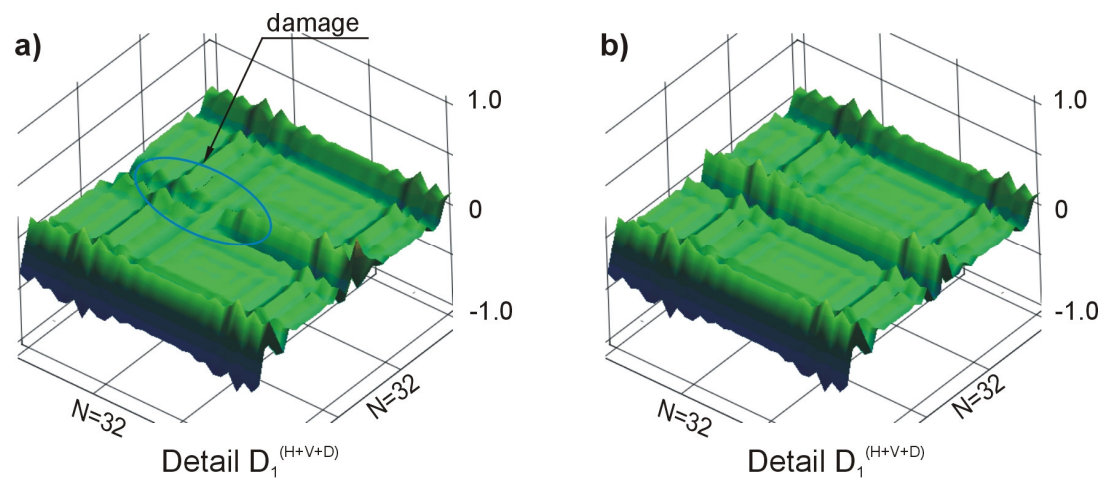

Fig. 14. Graphs of the 2-D DWT of temperature field using Daubechies 4 wavelet, time=504.0 s, (Example 3, defect 2): a) graph of detail $D_{1}^{H+V+D}$ with defect 2

b) graph of detail $D_{1}{ }^{H+V+D}$ without defect 2

\section{Conclusions}

IR thermography is a powerful tool which can support the inspections of the structure and equipment elements of bridges. Examination of the actual road viaduct using passive infrared thermography showed that this method can detect only the places of moisture, and optionally cover delaminations. Without external heat pulse (or any other excitation) it is impossible to detect damages caused by factors such as corrosion, fatigue and stress concentration in steel structures or discontinuity, delaminations and corrosion of reinforcement in concrete structures.

Numerical analyses demonstrated that DWT applied to thermal response signals of a defected structure is useful in damage detection. The efficiency of damage detection depended on its parameters.

In order to properly interpret thermal images of real construction should be perform tests on samples in a laboratory scale.

\section{REFERENCES}

[1] Bergamo O., Campione G., Donadello S., Russo G. "In-situ NDT testing procedure as an integral part of failure analysis of historical masonry arch bridges". Engineering Failure Analysis, Vol. 54, pp. 31-55, 2015

[2] Clark M.R., McCann D.M., Forde M.C., "Application of infrared thermography to the non-destructive testing of concrete and masonry bridges". NDT\&E International, Vol. 36, pp. 265-275, 2003

[3] Galmiche F., Vallerand S., Maldaque X. "Pulsed phase thermography with the wavelet transform". In. D.O. Thompson, D.E. Chimenti, eds. Review of progress in quantitative NDE, 19A, Am. Institute of Physics, pp. 609615,2000

[4] Izumi Y, Sakagami T., Kubo S., Tamakoshi T. "Detection of through-deck type fatigue cracks in steel bridges by self-reference lock-in thermography”. Proceedings of $14^{\text {th }}$ International Conference on Experimental Mechanics, EPJ Web of Conferences 6 (38011), pp. 1-8, published by EDP Sciences, 2010

[5] Kee Seong-Hoon et al., "Nondestructive bridge deck testing with air-coupled impact-echo and infrared thermography". Journal of Bridge Engineering 17, pp. 928-939, 2012

[6] Maldaque X., "Introduction to NDT by active infrared thermography". Materials Evaluation, Vol. 6, pp. 10601073, 2002

[7] Olbrycht R. et al. "Comparison of Fourier and wavelet analyses for defect detection in lock-in and pulse phase thermography". QIRT Journal, Vol. 4, pp. 219-232, 2007

[8] Różański L., Ziopaja K. "Wykorzystanie metod aktywnej termografii w podczerwieni do wykrywania defektów materiałowych". Inżynieria Maszyn, R. 18, z. 3, 2013

[9] Vaghefi Khatereh et al. "Evaluation of commercially available remote sensors for highway bridge condition assessment". Journal of Bridge Engineering 17, pp. 886-895, 2012

[10] Ziopaja K., Pozorski Z. and Garstecki A. "Damage detection using thermal experiments and wavelet transformation". Inverse Problems in Science and Engineering, 19(1), pp. 127-153, 2011 